\title{
2||-|||||||||||||||||||||||||||||||||||||||||||||||||||||||||||||||||||.
}

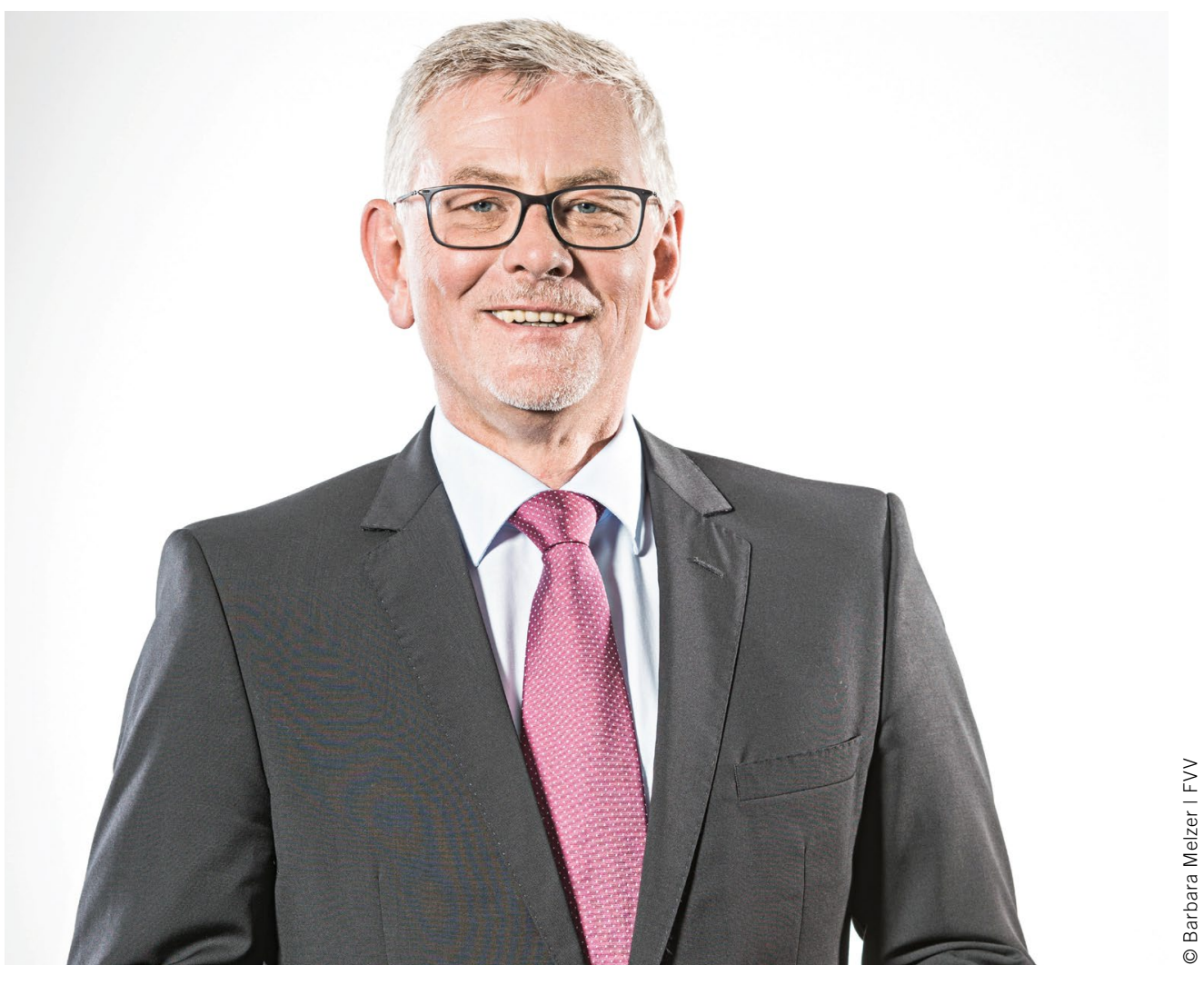

Dietmar Goericke

Managing Director of the Research Association for

Combustion Engines e. V.

in Frankfurt am Main (Germany)

\section{Hydrogen as a Platform Technology}

What do a harvester in 24-h operation, a wheel loader on a municipal construction site and a 60-t truck tractor for transporting timber in northern Europe have in common? Today, the one thing that connects such different vehicles is the diesel engine, which not only provides propulsion performance, but also supplies the energy for the work equipment. Powered by a fuel based on fossil crude oil, this universal prime mover was unbeatably practical! But if we are serious about defossilizing the entire economy, then it is necessary to adapt both the energy converter and the energy carrier for freight transport and all mobile machines as well. Is there a new universal solution for every application?

Apart from electrification with battery, which in the heavyduty sector quickly comes up against its limits, two mobile energy converters are currently being discussed more than any other: the fuel cell and the internal combustion engine powered by renewable fuels. Among the alternative fuels, there are a number of promising candidates. It seems difficult to imagine that a single energy converter, powered by a single fuel, will win the race for the future. However, if you look at the entire energy chain, that is to say from the wind turbine to the wheel, there is one common denominator in almost all approaches: hydrogen.
It can be produced on a large scale from renewable power with comparatively low losses. Hydrogen can be used directly in vehicles, or it can be further processed into familiar gaseous or liquid fuels using widely known processes. The number one in the periodic table of the elements does not represent a new universal solution. But in many cases it is the platform on which innovative, climate-friendly technologies are built. For this to happen, the right political course must be set, above all an ambitious implementation of the European Renewable Energy Directive II (RED II) in national legislation and standardization.

What does this mean for industrial collective research? The FVV pursues a dual approach: On the one hand, companies applying hydrogen define "bottom-up" the majority of all projects at the interface of energy carrier to energy converter. This is intended to remove those obstacles that still stand in the way of the economic application of hydrogen-based technologies. On the other hand, "top-down" fundamental issues are investigated, such as the life-cycle analysis of individual technology paths or the hydrogen infrastructure. Both approaches are absolutely necessary. Even if hydrogen is used as a platform technology, the powertrain world of the future will never be as simple as it is today! 